https://helda.helsinki.fi

\title{
Realizing the Potential of Immigrant Youth
}

Cambridge University Press

2012

Masten , A , Liebkind , K \& Hernandez , D (eds) 2012 , Realizing the Potential of Immigrant

Youth. The Jacobs Foundation Series on Adolescence, Cambridge University Press,

Cambridge . https://doi.org/10.1017/CBO9781139094696

http://hdl.handle.net/10138/234324

https://doi.org/10.1017/CBO9781139094696

acceptedVersion

Downloaded from Helda, University of Helsinki institutional repository.

This is an electronic reprint of the original article.

This reprint may differ from the original in pagination and typographic detail.

Please cite the original version. 


\title{
Specifying Social Psychological Adaptation of Immigrant Youth:
}

\author{
Social Identity, Intergroup Attitudes and Intergroup Interactions
}

Karmela Liebkind, Inga Jasinskaja-Lahti, and Tuuli Anna Mähönen

\section{Introduction}

Given that cultural diversity has the potential to put severe strains on the cohesion of communities, integration of immigrants can be regarded as a vitally important goal of multicultural societies. It is generally accepted that successful multiculturalism requires that all subgroups within a society will develop a real sense of belonging to the mainstream society, expressed as a national identity (e.g. Brewer, 2000; Report of the Community Cohesion Panel, 2004). While the importance of a common identity for positive intergroup relations to emerge has been highlighted for decades in social psychological studies, we argue in this chapter that the social-psychological aspects of immigrant integration has neither been properly defined nor sufficiently studied as an acculturation outcome of immigrant youth (Chryssochoou, 2004; Liebkind, 2001, 2006). In contrast to previous theorizations on attitudes and identities as cognitive acculturation outcomes (Arends-Tóth \& Van de Vijver, 2006; Masgoret \& Ward, 2006), we consider social psychological adaptation to encompass not only cognitive but also emotional, evaluative and behavioral components of social identity and intergroup relations (Liebkind, 2001; Simon, 2004; Verkuyten, 2005). Moreover, we propose that the development of complex and flexible social identities (including both national and ethnic components), positive intergroup attitudes and positive intergroup interactions are the essence of social-psychological adaptation and successful integration.

In adolescence, the task of developing positive intergroup attitudes and intergroup interactions coincides with the developmental stage in which immigrant youth have to negotiate and solidify their identity (Erikson, 1968). In addition, ethnic minority identities can in multicultural societies be seen to represent subordinate group identities within the national superordinate group. 
Immigrant youth can perceive these two cultural identities to be mutually oppositional or even exclusive (Benet-Martinez \& Haritatos, 2005). Also Verkuyten and Yildiz (2007) have noted that ethnic minority identities may, when perceived to be threatened in one way or another, become oppositional to the national identity. Ethnic minority identity derives from membership in an ethnic group. In this chapter, "ethnic group" refers to a group whose members believe that they share some common ancestry and cultural characteristics such as language, habits and/or religion (e.g., the Finns, the Russians). It should be kept in mind that, at least in Europe, both majority and minority groups "have cultures" and "are ethnic" in this sense; ethnicity is not a feature of minority group members only.

However, the development of ethnic and national identities does not happen in a social vacuum. Instead, social identities, intergroup attitudes and interactions influence each other reciprocally (Simon, 2004; Verkuyten, 2005). How we perceive self and other is related to processes of identity definition (Drury \& Reicher, 2000; Reicher, 2004). For immigrant youth, ethnic and national identities thus play a crucial role, mediating between experiences and behavior: identities both follow and precede interaction in the social world (Reicher, 2004; Simon, 2004). Research at the interface of social and acculturation psychology has, for example, focused on the effects of perceived discrimination that make it hard - or impossible - for ethnic minority members to identify with the superordinate national group (e.g., Jasinskaja-Lahti, Liebkind, \& Solheim, 2009). Minority members' contacts with the majority group as well as their intergroup attitudes and identification options largely reflect their feelings of acceptance by and inclusion in the larger society (e.g., Branscombe, Schmitt, \& Harvey, 1999), and feelings of rejection are found to harm the intergroup relations between ethnic majority and minority groups (e.g., Barlow, Louis, \& Terry, 2009; Shelton, Richeson, \& Vorauer, 2006).

In this chapter we apply a social psychological approach to immigrant adaptation ${ }^{\mathrm{i}}$ focusing on the reciprocal and interactive nature of intergroup attitudes as consequences of and antecedents 
to ethnic and national identity among immigrant youth. More specifically, we take a threat perspective to the attitude formation and identification patterns of minority youth. The concept of threat has been defined in various ways, but in this chapter, the definition of each kind of threat has been derived from its specific implications for identity (Breakwell, 1986, p. 46). Two forms of identity threats are especially relevant for the purpose of the present chapter. First, threatening information or behavior can be intentionally directed at the ingroup by the outgroup and take the form of discrimination (Branscombe, Ellemers, Spears, \& Doosje, 1999). Second, there are also more indirect identity threats related to the conflicting motivations and aspirations of majority and minority group members. The question of cultural maintenance - whether or not the immigrant feels that her/his wish to maintain the heritage culture in the new society is approved by the majority - is crucial for immigrants' motivation to integrate in the society (e.g., Berry, 1997; Bourhis, Moise, Perreault, \& Senecal, 1997).

Thus, cultural discordance, i.e., disagreement between majority members and immigrants regarding the latter's degree of adherence to their heritage culture, can be seen to represent an indirect threat to the value of minority group members' identity. This threat influences the outgroup attitudes and identification patterns of minority group members (Rohmann, Florack, \& Piontkowski, 2006; Mähönen, Jasinskaja-Lahti, \& Liebkind, 2011). In this chapter we will first present a literature review on the social psychological adaptation of immigrant youth and on the threats of perceived discrimination and cultural discordance. Next, we illustrate the reviewed research with some new empirical results on the effects of these threats on the identities and intergroup attitudes of immigrant youth. We then conclude with an overview of practical remedies for improving intergroup relations among youth. 


\section{Social Identities, Intergroup Attitudes and Intergroup Relations}

\section{Intergroup Attitudes in Childhood and Youth}

Social psychological adaptation is very much dependant on reciprocally positive intergroup attitudes. Intergroup attitudes emerge in early childhood and can have a profound impact on social relations for a lifetime (Gaertner et al., 2008). The extent and quality of social relations with both in- and outgroup members are especially important in adolescence for the development of both intergroup attitudes and social identities (Phinney, Berry, Vedder, \& Liebkind, 2006). In addition to the normative identity exploration that all youth undergo, ethnic minority youth crystallize and formulate an identity also related to their racial and ethnic group membership (Phinney et al., 2006).

However, research literature presents mixed evidence regarding the developmental sequence of intergroup attitudes among children and adolescents in that some studies indicate a development towards more positive intergroup attitudes while others indicate development towards more negative intergroup attitudes: The development of intergroup attitudes among children and adolescents depends on a combination of cognitive and social factors (Barrett, 2007; Abrams \& Rutland, 2008). On the one hand, intergroup bias is found to decrease in adolescence due to the increasing capability to fairness judgments and to the greater adherence to social norms (Enesco, Guerrero, Callejas, \& Solbes, 2008). Age has been found to be positively associated with social perspective-taking ability, which, in turn, is associated with a better understanding of how groups operate and apply norms (Abrams \& Rutland, 2008). On the other hand, stereotypic expectations also are found to increase with age. Moreover, not all children and adolescents respond according to accepted social values and expectations, and adolescents who are surrounded by a highly prejudiced environment will probably maintain prejudiced attitudes despite their newly developing cognitive

capabilities (Enesco et al., 2008). Finally, implicit, in-group-serving biases are suggested to develop early and to largely remain invariant over time, even though the explicit attitudes change (Banaji, Baron, Dunham, \& Olson, 2008). 
In the literature on the development of intergroup attitudes and relationships among children and adolescents it can be noted that much more research has been conducted on the attitudes of majority or high-status group members relative to the attitudes of minority or low-status group members. It may not be surprising given the history of the former's perpetuating prejudice towards minority groups, but a full understanding of intergroup relations and the development of prejudice requires the study of all groups. (Killen \& Levy, 2008.)

\section{The Relationship between Social Identity and Intergroup Behavior}

In multicultural contexts, intergroup attitudes guide intergroup behavior. Such behavior occurs when members of one group act towards members of another group in terms of their group memberships rather than for personal or idiosyncratic reasons. According to Social Identity Theory (SIT) social identity processes have implications for intergroup behavior (Tajfel, 1978; Tajfel \& Turner, 1986). SIT proposes that people's group memberships are incorporated into their selfconcepts, and when people's category memberships become salient in a social situation, intergroup differentiation and intragroup assimilation emerge; similarities between members of the ingroup and differences between in- and outgroup members are exaggerated. SIT maintains that groups seek positive distinctiveness from other groups and that this is usually achieved by favorable social comparison (Tajfel \& Turner, 1986). Favorable comparisons are not identical to outgroup discrimination, although it can be manifested also as discriminative behavior (Reicher, 2004).

Because of our presumed need for a positive self-concept, it follows that there will be a bias in social comparisons to look for ways in which one's own group can be distinguished favorably from other groups. Intergroup bias thus refers to the systematic tendency to evaluate the ingroup and its members more favorably than the outgroup and its members. This group-serving tendency can take the form of favoring the ingroup and/or derogating the outgroup (Hewstone, Rubin, \& Willis, 2002). Children as young as six years of age display remarkably similar tendencies as adults to enhance the standing of their ingroup at the expense of outgroups and display prejudice and 
discrimination against selected outgroups (Nesdale, 2008). However, both social and developmental psychologists have emphasized the need for making a distinction between ingroup and outgroup aspects of intergroup behavior; ingroup preference cannot be equated with outgroup evaluation (Verkuyten, 2008). Prejudice specifically connotes outgroup derogation, or negativity toward outgroups (Bohner, 2001; Pfeifer et al., 2007).

Besides ingroup favoritism or outgroup derogation, group members might use also other strategies to enhance their group identity. Following Tajfel and Turner $(1979,1986)$, the strategic options are (1) leaving the negatively evaluated group, (2) changing the level of categorization, (3) social competition to change the status relations or the allocation of resources between groups, (4) changing the dimensions of evaluation, and (5) changing the reference group of evaluation (Tajfel \& Turner, 1979, 1986). The search for positive group distinctiveness is one of the basic findings of social psychology, possibly because ingroup loyalty cannot be maintained without clear group boundaries (Brewer, 1991). Intergroup behavior tends to occur whenever one or more social identity is salient, and this is often the case when immigrant youth interact with the native population of a country.

\section{Factors Influencing Intergroup Attitudes and Relations Between Minority and Majority Youth}

\section{The Role of Ethnic and National Identities}

Ethnic identity is generally seen as embracing various aspects, including self-identification, feelings of belongingness and commitment to a group, a sense of shared values, and attitudes towards one's own ethnic group (Liebkind, 2006). In a number of studies, ethnic identity is defined simply as the ethnic component of social identity (Liebkind, 1992). Ethnic identity becomes especially central during adolescence. Ethnic minority adolescents must not only negotiate the identity formation process in terms of interpersonal relationships and occupation, but must also contend with their 
minority group status within the majority culture and define how this cultural aspect of their identity informs who they are and who they will become. (Umana-Taylor \& Upgredaff, 2007.)

Within social psychology, the strength of identification with one's ingroup has often been assumed to correlate positively with ingroup favoritism or outgroup derogation, and some research at least among adults has supported this hypothesized relationship (e.g.,Hodson, Dovidio, \& Esses, 2003; Liebkind, Nyström, Honkanummi \& Lange, 2004; Perreault \& Bourhis, 1999). Also contradictory findings have been presented. For example, research looking especially at ethnic identity development in adolescents and young adults has suggested that strong ethnic identities constitute markers of maturity, consideration of intergroup differences, and are ultimately associated with less intergroup bias (Pfeifer et al., 2007; Phinney, Jacoby, \& Silva, 2007; Phinney, Ferguson, \& Tate, 1997; Wittig, 2008). Thus, a strong ethnic identification of minority members may in some contexts imply positive and in other negative attitudes towards the national outgroup (i.e., the majority/majorities of the country of settlement).

The mixed results may partly originate from the different aspects of ethnic identity measured, as few investigators have measured the pertinent social identities in any detailed manner. For example, when operationalizing ethnic identity as the centrality and personal evaluation of or personal affect towards membership in the ethnic group (instead of studying the strength of identification per se), Pfeifer et al. (2007) found children's strong ethnic identity to be related to higher ingroup favoritism. Moreover, minority children who reported a stronger national than ethnic identity demonstrated significantly less both ingroup favoritism and outgroup derogation (Pfeifer et al., 2007).

Another reason for the mixed results may be that the relationship between social identity and intergroup attitudes is age-related. Although social identity theory is not explicitly developmental, it implies, in contrast to cognitive developmental theory (Aboud, 1988), that children's intergroup attitudes are likely to become more biased with age as ethnic or other social identities become 
incorporated into the self-concept (Abrams \& Rutland, 2008). According to Pfeifer and her colleagues (2007), however, both SIT and cognitive developmental theory may be right: as children increasingly identify with relevant social groups they do become more likely to make social comparisons that positively differentiate their ingroup from relevant outgroups. Thus, intergroup bias may be expected to increase with ethnic identity strength in accordance with classic group identity effects at the earliest stages of ethnic identity development, but a more complex understanding of ethnic identity could possibly be achieved only after going through all the stages of identity development. (Pfeifer et al., 2007.)

As noted before, however, social identities and intergroup relations (attitudes, contact and interaction) influence each other reciprocally (Drury \& Reicher, 2000; Simon, 2004; Verkuyten, 2005). Social identities both follow from and precede intergroup interaction (Reicher, 2004; Simon, 2004). Interactions are pivotal also for intergroup attitudes (Dovidio, Glick, \& Rudman, 2005). Research on adult populations has addressed both causal directions: how intergroup interactions or contact influence intergroup attitudes (the Contact Hypothesis, e.g., Binder, et al. 2009; Dovidio, Gaertner, \& Kawakami, 2003) and how intergroup attitudes affect intergroup behavior (discrimination and contact; Pettigrew \& Tropp, 2006). However, group size and group status influence the level of reciprocity between social identities and interactions; by virtue of their advantaged demographic, status and institutional control position, the attitudes of majority members are likely to have a stronger impact on the identities and intergroup attitudes of minority members than vice versa (Bourhis et al., 1997).

\section{Integrating Ethnic and National Identities}

Among adolescents and adults alike, ethnic and national identities may, but do not necessarily, conflict with each other (e.g. Phinney, Horenczyk, Liebkind, \& Vedder, 2001; Phinney et al., 2006; Verkuyten, 2005, 2007). Immigrants and ethnic minorities differ in the extent to which they perceive their cultural identities as largely integrated and compatible or dissociated and difficult to 
integrate (Benet-Martinez \& Haritatos, 2005). Empirically, the correlation between national and ethnic identity has varied from zero association to strong positive or negative association, regardless of the age of the respondents (e.g., Phinney et al., 2001; Verkuyten, 2005).

Individuals may integrate their multiple social identities in different ways: the content of minority identities may include varying proportions of minority/ethnic and majority/national components, and these two components may be parallel or hierarchical. Within acculturation research, integration has a distinct meaning as an acculturation orientation that is shown by individuals who want to retain their heritage culture and/or identity while also adopting the majority culture (e.g., Berry, Phinney, Sam, \& Vedder, 2006). However, the integration orientation varies considerably depending on whether the orientation towards the country of settlement is defined in terms of identity (Hutnik, 1991), culture (Bourhis et al., 1997), or contact (Berry, 1997; Berry et al., 2006). Immigrants may be far less inclined to identify with the dominant society or to adopt parts of its culture (while simultaneously retaining their heritage culture and/or identity) than to have regular contact and good relationships with the majority population and participate in the society (Snauwaert, Soenens, Vanbeselaere \& Boen, 2003). In addition, the integration orientation can refer to any proportion of the mainstream culture (or identity) and the heritage culture (or identity) preferred or adopted (Simon \& Ruhs, 2008), to shifting from the one to the other depending on context, or to the creation of a "new" culture or identity (Arends-Toth \& van de Vijver, 2006; Liebkind, 2001; Verkuyten, 2005). As noted before, immigrants can also, to varying degrees, perceive the mainstream culture (or identity) and their heritage culture (or identity) as oppositional (Benet-Martinez, Leu, Lee \& Morris, 2002).

Identity integration requires reduction of a possible conflict between different identities through two alternative solutions: if the two identities (ethnic and national) are compatible rather than oppositional (Amiot, de la Sablonnière, Terry, \& Smith, 2007; Benet-Martinez \& Haritatos, 2005) they can be integrated into a new cultural hybrid identity. Provided that a superordinate 
identity allows for sufficient complexity and diversity in how it is construed (Hornsey \& Hogg, 2000a, 2000b), a second solution is to consider the national identity as a superordinate category (Amiot et al., 2007): immigrants may perceive their own ethnic group and the national outgroup as subgroups of a common, superordinate (national) in-group. The degree of compatibility of different identities has been found to be associated with positive intergroup attitudes and interactions (BenetMartinez \& Haritatos, 2005).

In order to prevent or overcome a conflictual relationship between superordinate/national and subgroup/ethnic identification, different theoretical models within the SIT framework have been formulated. While some research has assumed that total de-categorization - playing down all group memberships - is the key to harmonious intergroup relations (e.g., Brewer 1999), other research suggests that if members of two groups could re-categorize themselves as belonging to a single superordinate category more favorable attitudes towards all the fellow members of new, larger ingroup should ensue (Gaertner et al., 2008). However, the fundamental limitation of both decategorization and recategorization models is that they threaten to deprive individuals of valued social identities in smaller, less inclusive groups (Brewer 1999; Crisp, Stone \& Hall, 2006). The prospect of a superordinate group identity may constitute a threat which actually increases bias; a common in-group identity may be unrealistic in the face of powerful ethnic categorizations and many minorities are likely to resist assimilation into a superordinate category that is dominated by a majority outgroup, (Brewer 2000, Hornsey \& Hogg 2000a, 2000b).

The dual identity model (Gaertner et al. 2008; Dovidio, Gaertner, \& Saguy, 2007) aims to remedy these problems. A dual identity encompassing both national and ethnic identity refers to a context "...in which subgroup identities are maintained within the context of a superordinate entity...” (Gaertner et al., 2008, p. 145). This model acknowledges simultaneously the need to belong to a superordinate nation state (similarity at the superordinate level of identification) and the need to be different (distinctiveness at the subgroup level of identification), thereby supplying 
optimal distinctiveness (Brewer, 1991; Dovidio, Gaertner \& Saguy, 2007; Hornsey \& Hogg, 2000a, Hornsey \& Jetten, 2004). Nested or common ingroup identities have been found to foster positive intergroup relations only if they represent sufficiently inclusive and complex superordinate national identities which transcend cultural boundaries and facilitate successful intergroup contacts (Gaertner et al., 2008; Hewstone et al., 2002; Hornsey \& Hogg, 2000a, 2000b; Stone \& Crisp, 2007; Waldzus, Mummendey, \& Wenzel, 2005). Possessing a sufficiently inclusive superordinate group identity in addition to a subgroup identity (i.e., having a dual identity) can reduce biases at the subgroup level also among children and adolescents (Pfeifer et al., 2007). Some developmental research (Cameron \& Rutland, 2008) suggests that the effectiveness of the dual identity approach may be age dependent: older (at least 9 years) rather than younger children can simultaneously consider subordinate and superordinate categories. This suggests that the positive effects of dual identity may be limited to older children, as the cognitive capacity required for integrating multiple selves and resolving conflicting identities develops over time.

However, contrary to their developmental prediction, Cameron, Rutland, Brown, and Douch (2006) found in an extended contact intervention in a British elementary school that both a dual identity and simply a common ingroup identity were equally effective among younger and older age groups. Cameron et al. (2006) devised an intervention that consisted of reading several stories to children that portrayed friendships between majority and refugee children. In some of these stories the category memberships of the protagonists were little emphasized and their individual identities were stressed (decategorization); in others the superordinate (school) category membership was a recurring theme (common ingroup identity); in still others, the subgroup identities of the protagonists as host majority members and refugees were salient while simultaneously underlining their common school identity (dual identity). There was also a control group of children who were exposed to no stories. The dual identity intervention was the most effective extended contact model. Although the intervention was more effective in changing children's intended outgroup behavior 
than it was for changing intergroup attitudes, this study shows that prejudice-reduction tools designed on the basis of social psychological identity processes are effective in children as young as 5 years old (Cameron et al., 2006.)

The results of social psychological studies on dual identity parallel findings in acculturation research, where clear benefits of dual or accumulative identification have been shown for immigrants' well-being and intergroup relations: secure and positive dual identity is found to be associated with better well-being and more positive attitudes towards outgroups (e.g., Berry et al., 2006; Brewer \& Pierce, 2002; Horenczyk \& Ben-Shalom, 2001; Phinney \& Alipuria, 1996). On a more general level, however, one major problem for the dual-identity approach is that members of majority and minority groups may have different preferences for the content of the superordinate identity, i.e., what that identity and the relations between the subgroups within it should be like. Although both majorities and minorities may prefer identity integration as a goal, majority members may mean a more assimilative and minority members a more separate identity with the term (Jasinskaja-Lahti, Liebkind, Horenczyk \& Schmitz, 2003; Phinney et al., 2001). Overall, however, both social and acculturation psychologists seem to agree that maintaining a positive subgroup identity within a common superordinate identity is the best option from the viewpoint of positive intergroup relations. It is possible, however, that a bicultural identity does not necessarily require a positive relationship between the two identities: strong ethnic and strong national identities can coexist in an integrated identity even when the two identities are independent of each other (Mähönen et al., 2011).

Importantly, different factors may prevent immigrants from identifying with the superordinate national group. Even if cultural differences are not perceived to be insurmountable, negative intergroup interactions, such as perceived discrimination or cultural discordance may effectively prevent the favorable development of national identification and positive outgroup attitudes. These detrimental effects will be addressed next by combining SIT driven lines of 
theorization with research that takes more strongly into consideration the impact of the social context on identities and intergroup relations.

\section{The Role of Negative Acculturation Experiences}

\section{Perceived Discrimination}

The migration experiences most likely to influence social psychological and other dimensions of integration include perceived discrimination (e.g., Bourhis et al., 1997). The bulk of research on the link between discrimination and adaptation has focused on the psychological aspects of immigrant adaptation. A consistent and robust finding among adult and adolescent immigrants alike is that perceived discrimination has direct and strong impact on the psychological well-being and health of immigrants, e.g., depression, low self-esteem, delinquency, and substance use (e.g., Williams, Neighbors, \& Jackson, 2003; Jasinskaja-Lahti, Liebkind, \& Perhoniemi, 2006; Rivas-Drake, Hughes, \& Way, 2008; Seaton, Yip, \& Sellers, 2009).

Perceived discrimination is also a serious obstacle for ethnic groups to achieve a sense of national identity and for harmonious intergroup relations. Ethnic minority group members' contacts with the majority group as well as their intergroup attitudes and identification options largely reflect their feelings of acceptance by and inclusion in the larger society (e.g., Branscombe et al., 1999; Jasinskaja-Lahti et al., 2009). Research suggests that perceived discrimination encourages hostility among minority members towards the national outgroup (e.g., Schmitt \& Branscombe, 2002). Similarly, Nesdale (2008) has found that children as young as 7-10 years old react to peer group rejection by expressing prejudice towards the rejecting group.

Ethnic minority members have been found to cope with the experience of being discriminated against 1) by seeking to assimilate into the majority by increasing national identification (e.g., Rumbaut, 2008), 2) by developing a "reactive ethnicity" (the RejectionIdentification Model, RIM; e.g., Branscombe et al., 1999), also referred to as a re-ethnicisation process (Skrobanek, 2009, see also Rumbaut, 2008), or 3) by reducing national identification (the 
Rejection-Dis-Identification Model, RDIM; Jasinskaja-Lahti et al., 2009; Verkuyten, 2008).

According to Rumbaut (2008), assimilation is the modal response of the children of European immigrants in the American experience that is characterized by ethnic identity shifts towards the "thinning" of their ethnic identities. This can be seen to partly reflect the high degree of social mobility and intermarriage with the majority population among the white European immigrants as well as a relatively positive context of their reception and low degree of prejudice and discrimination towards this group in the core society. However, the reception of White European immigrants in the USA has not been totally unproblematic; especially during the earlier waves of immigration also they have experienced considerable discrimination (Alba, 1996; Diner, 1996; Gold \& Phillips, 1996).

In case of culturally more distant and/or socially disadvantaged groups, perceived discrimination against one's social ingroup has, in accordance with RIM, been found to increase ingroup identification (Schmitt \& Branscombe, 2002; Outten, Schmitt, Garcia \& Branscombe, 2009). This identity reaction may be seen as an effort to maintain a positive self-image, as social identity is defined as the person's awareness of membership in, and the emotional value and significance attached to a specific social group (Tajfel, 1978). Although RIM has received impressive empirical support, particularly among African-Americans (for a review, see Schmitt \& Branscombe, 2002), in some studies the relationship between perceived discrimination, ethnic identity and well-being has not been found (i.e., Jasinskaja-Lahti et al., 2009). This was explained by a high degree of in-group identification obtained among the immigrants studied (i.e., Russianspeakers in Finland): minor increases in ingroup identification probably do not significantly enhance psychological well-being or may not be a desirable option in cases where the in-group is likely to be a consistent target of pervasive derogation.

Even if reactive ethnicity may buffer against the negative consequences of perceived discrimination, studies with ethnic minority samples in Europe and the United States indicate that, 
when talking about low status groups, the positive effects may not be confined to well-being: a stronger sense of belonging to one's group may also be associated with more positive attitudes toward outgroups (e.g. Phinney et al., 2007; Verkuyten, 1992). Thus, it seems that minority members' negative attitudes towards the national majority may be related to the national and not the ethnic dimension of their social identity. However, the RIM largely ignores the coexistence of these two meaningful identity dimensions among immigrants and ethnic minorities. The role of each of these identities in the adaptation process of immigrant youth should be considered separately as they may interact and/or have different psychological consequences (Jasinskaja-Lahti et al., 2009).

People's willingness to act in favor of any group (e.g., the national society) to which they belong flows from the "identity information" they receive from that group (Simon, \& Stürmer, 2003; Tyler \& Blader, 2003). With continuing negative "identity information," the immigrants may resort to separatist identities (Simon \& Ruhs, 2008; Verkuyten, 2007) or re-ethnicisation (Skrobanek, 2009). If, then, the perception of ethnic discrimination stemming from the national society is experienced as unfair treatment, it can be assumed that these experiences will discourage immigrants from identifying with the superordinate national group and result in a tendency to disengage from it (i.e., national disidentification). This disidentification, in turn, may result in increased hostility towards the national majority. (Jasinskaja-Lahti et al., 2009.)

The RDIM (Jasinskaja-Lahti et al., 2009) suggests that perceived discrimination may in some contexts prevent minority members from developing a sense of belonging to a superordinate group. As a result, disidentification from and hostile attitudes towards the superordinate national group will occur (Jasinskaja-Lahti et al., 2009). The RDIM also suggests that decreased national identification may mediate the effect of perceived discrimination on attitudes towards the national majority. In a study of the relationship between perceived discrimination and national identification among immigrants from 13 countries (Berry at. al.,, 2006), immigrant adolescents who felt that they were being discriminated against tended to reject a national identity by disidentifying from the 
national majority group. In contrast, those who did not feel discriminated against were likely to show national identity profiles. Thus, perceived discrimination was clearly associated with immigrants' tendency to distance themselves from the larger society. In addition, Verkuyten and Yildiz (2007) found increased ethnic identification to serve as a partial mediator of the negative effect of perceived rejection on national identification.

\section{Cultural Discordance}

The strength of ethnic and national identifications and subsequent outgroup attitudes of minority members depend not only on perceived discrimination, but also on more indirect threats posed by negative policies, discourses, and attitudinal climate in the society at large (Bourhis et al., 1997). The political climate, reflected in public discourse, has been shown to impact the intergroup attitudes of 18-26-year-old immigrants; Verkuyten and Zaremba (2005) found in their longitudinal study that after the public discourse in the Netherlands had turned radically against Muslim immigrants and multiculturalism in 2001-2002, identity concerns changed the subsequent attitudes of immigrants of Turkish descent towards both the Dutch and other ethnic outgroups in a negative direction.

Cultural diversity in the society stimulates immigrants' integration only if there is a match between the diversity policy of the society and the expectations of immigrants (Bourhis et al., 1997). Problems usually arise when the society puts pressure on cultural minorities to adjust to dominant national identities that do not allow for inclusion of aspects of the heritage culture. This pressure usually results from lack of appreciation for the diversity represented by the minority groups. In recent studies, this kind of denigration of minority group membership has been approached though the concepts of low public regard (Seaton et al., 2009), identity undermining (Sindic \& Reicher, 2009), and cultural discordance - a disagreement between majority members and immigrants regarding the latter's degree of adherence to their heritage culture (Rohmann, Florack, \& Piontkowski, 2006). As a consequence of these kinds of identity threats, people are likely to reject membership of superordinate bodies, as any superordinate identity must be viewed "as a source of positive identity that does not conflict with or contradict cherished attributes of 
subgroup identity” (Hornsey \& Hogg, 2000a, 143, see also Branscombe, Ellemers et al., 1999; Sindic \& Reicher, 2009).

The concordance or discordance of the acculturation attitudes of majority and minority groups (i.e. whether the immigrant values her/his heritage culture and thus desires to maintain it in the new society, and whether she/he feels that this maintenance is allowed and even approved by the majority) is crucial for the adaptation and integration of immigrants in the society (Ait Ouarasse \& Van de Vijver, 2004; Berry, 1997; Berry et al., 2006; Horenczyk \& Munayer, 2007; Pfafferott \& Brown, 2006). The concordance model of acculturation (CMA) proposes that the greater the mismatch in acculturation attitudes, the more threatening and less enriching the intergroup situation will be perceived to be, and that high values of culture discordance indicate that immigrants prefer to maintain their culture to a higher degree than they think is accepted by the host community (Piontkowski, Rohmann \& Florack, 2002; Rohmann et al., 2006, p. 689). Immigrants often experience cultural discordance, i.e., they perceive the majority group's expectations of immigrant assimilation as considerably stronger than their own willingness to assimilate (e.g., Horenczyk, 2000). However, far less is known about the reactions to and consequences of negative experiences of this kind than of the reactions to perceived discrimination.

\section{The Joint Effects of Perceived Discrimination and Cultural Discordance}

Even though both perceived discrimination and cultural discordance represent negative acculturation experiences, the identity consequences of the former have mainly implied changes in the strength of ethnic and national identification, whereas the latter can be assumed to have consequences also for the relationship between the two identity dimensions. In our recent study among Russian-speaking immigrant adolescents living in Finland (Mähönen et al., 2011), we showed that negative acculturation experiences such as perceived discrimination and cultural discordance had a crucial but distinct impact on the identification patterns. According to the results obtained, both perceived discrimination and cultural discordance had a negative effect on the 
national identification of ethnic minority youth. However, their ethnic and national identifications were negatively associated and appeared as oppositional only when there was a perceived discordance between one's own wish to maintain one's heritage culture and the perceived attitude of the majority group towards immigrants' maintenance of their ethnic heritage. When no cultural discordance was experienced and, in fact, immigrant youth felt that their adherence to their heritage culture was supported, ethnic and national identification were independent of each other. In contrast, perceived discrimination had only a direct negative effect on the national identification of immigrant youth (cf., RDIM, Jasinskaja-Lahti et al., 2009) and perceived discrimination did not moderate the association between ethnic and national identification.

In the light of these results, we suggest that immigrant youth react differently to direct and indirect identity threats (Mähönen et al., 2011). When immigrant youth are confronted with direct and intentional discrimination (Branscombe, Ellemers et al., 1999), they can react to it in a straightforward manner by acting upon just one of their two group identities - either by increasing their ethnic identification (Branscombe et al., 1999) or by decreasing their national identification (Jasinskaja-Lahti et al., 2009; see also Verkuyten \& Yildiz, 2007). However, when cultural discordance is experienced as a result of the perceived conflict between the aspirations of the national majority and the immigrants, it represents a threat to the value (Breakwell, 1986) and/or distinctiveness (Branscombe, Ellemers et al., 1999) of the immigrant's ethnic identity. Thus, the identity reaction to this kind of threat requires the positioning of oneself in relation to both groups simultaneously, resulting in the polarization of the two identities. This could explain why, in the study by Mähönen et al. (2011), cultural discordance, but not perceived discrimination, moderated the relationship between ethnic and national identification, although both of these acculturation experiences had direct negative effects on the national identification of immigrant youth. The identity processes caused by direct and indirect identity threats have implications also for the intergroup attitudes of minority youth. An additional analysis of the same data revealed that both 
threats had a negative impact on outgroup attitudes, either directly (perceived discrimination) or indirectly through lowering the level of national identification (both threats, cf. Figure 8.1).

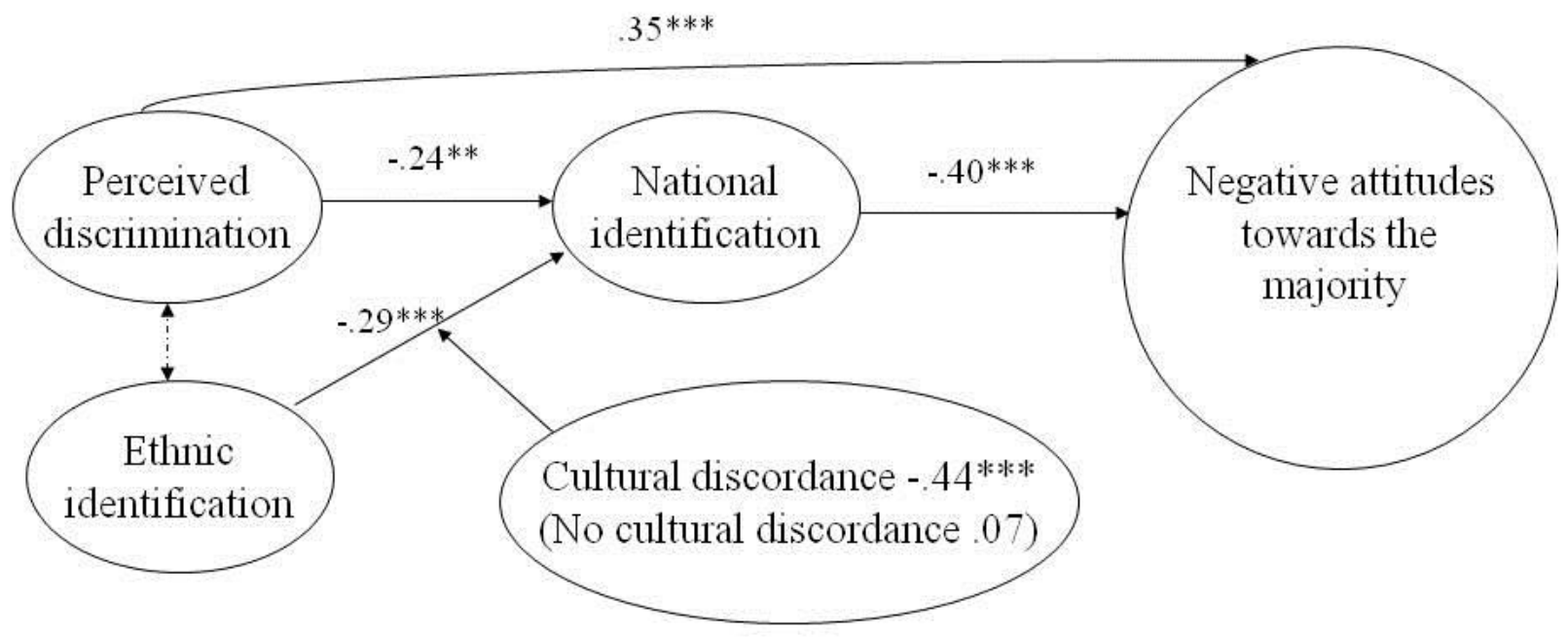

$X^{2}=656 ; d f=2 ; p=.720$

Note: The model is controlled for age at arrival. Perceived discrimination, ethnic identification and age at arrival were set to correlate in the model. All correlations were non-significant. In a hierarchical regression analysis cultural discordance was negatively and significantly related to national identification.

Figure 8.1

It thus looks as if negative acculturation experiences could lead to a vicious circle of social psychological maladaptation. Perceived discrimination and perceived cultural discordance seem to lead to increased hostility towards and separation from the national group. This, in turn, may predispose immigrant youth to even more perceived discrimination as it may make the majority especially an insecure majority (Liebkind, 1992; Moscovici \& Paicheler, 1978; Simon et al., 2001) - resort to even more discriminatory behavior (Jasinskaja-Lahti et al., 2009). Results from the longitudinal study by Seaton and colleagues (2009) showed that incidents of ethnic discrimination reinforced adolescents' notion that general society has a negative perception of their ethnic ingroup, which further increased perceptions of ethnic discrimination. Thus, experiences seem to predict 
views, social identities and intergroup attitudes, which seem to predict experiences (Seaton et al., 2009).

These results emphasize the need for an inclusive superordinate national identity and call for a shift in emphasis: if the national identity is perceived to be inclusive enough, identity negotiations between immigrant youth and majority members can change from those concerning the immigrants' ethnic identity to those concerning the common national identity. This does not mean that ethnic identities should not be negotiated, but that those negotiations must also include the ethnic identity of the majority population: the latter must not coincide with national identity. A sufficiently inclusive superordinate national identity requires a balance between protecting people's needs for group distinctiveness and ensuring that this security does not evolve into ethnocentrism or an overly rigid policing of intergroup boundaries (Hornsey \& Hogg, 2000a).

\section{Conclusions - What can be Done?}

Social psychological adaptation among immigrant youth in terms of positive intergroup attitudes and interactions and concomitant complex and flexible social identities has only recently become a focus of attention among politicians and researchers who recognize the potential dangers of intergroup tensions in the future. The research reviewed in this chapter clearly points to the detrimental influence of negative acculturation experiences such as perceived discrimination and cultural discordance on identity formation and intergroup attitudes of immigrants, particularly immigrant children and youth. If membership groups are valuable to self-conception, individuals want to maintain the perception of them as being (a) positive and (b) clearly distinguishable from other, relevant, comparison groups (Crisp \& Beck, 2005). Perceived discrimination and cultural discordance threaten the achievement of these motivational goals among children and adults alike (Verkuyten, 2008).

Consequently, research emphasizes the importance of positive acculturation experiences for successful adaptation of immigrant youth. Particularly, research has tried to 
(1) identify buffering factors which increase the resilience of immigrant youth in the face of negative acculturation experiences (e.g., Rivas-Drake et al., 2008), and to

(2) find interventions to curb the occurrence of their negative acculturation experiences (e.g., Paluck \& Green, 2009; Turner \& Brown, 2008).

For example, some theorists (Branscombe et al., 1999; Schmitt \& Branscombe, 2002) have suggested that having positive affect toward one's own ethnic group may buffer, or protect, minority youth from the negative outcomes that have been attributed to discrimination. However, as noted above, the results regarding the relationship between perceived discrimination and positive affect towards one's ethnic group among youth are mixed (Rivas-Drake et al., 2008; Seaton et al., 2009).

There is, however, another important factor that may also protect youth from ethnic discrimination but which has been remarkably understudied, namely, perceptions of public regard immigrant youths' perceptions of the majority members' views of their ingroup (Rivas-Drake et al., 2008). The buffering effects of high public regard should not be overlooked: Seaton and colleagues (2009) found that perceived discrimination influenced in a negative direction adolescents' beliefs of others' evaluations, i.e., their perceptions of public regard. Rivas-Drake and colleagues (2008), in turn, found that more favorable public regard, but not positive affect towards their own group, functioned as a protective factor for Chinese American youth who perceived discrimination.

Perceptions of how majority members value one's ingroup derive from the environment which consists of interrelated and nested structures like family, peers, school, neighborhood, and society. On a societal level, immigrant policies still revolve primarily around demands that are made of immigrants and how they should adapt, ignoring the fact that successful integration of minority groups also requires the majority group to provide opportunities and remove obstacles. For example, European multiculturalism has always been targeted at immigrants and minorities rather than the majority group (Verkuyten, 2008). 
Therefore, attempts to address the social psychological adaptation of immigrant children and youth from an intergroup perspective should include efforts to prevent or reduce negative acculturation experiences at their roots. As intergroup stereotypes and prejudices emerge already in early childhood (Abrams \& Rutland, 2008), childhood and adolescence are strategically the optimal periods to begin to assault the cognitive, motivational, and cultural forces that contribute to the development of prejudice (Gaertner et al., 2008) in both majority and minority children. For the past 50 years, intergroup contact theory (Allport, 1954) has represented one of psychology's most effective strategies for improving intergroup relations. This theory poses that intergroup contact fosters intergroup harmony when the participants are of equal status in the contact situation, the interaction is cooperative rather than competitive, it has common goals and support from authorities, law or custom, and sufficient friendship potential (Dovidio, Gaertner, Saguy, \& Halabi, 2008). Important mediators of the contact-attitude link include the reduction of intergroup anxiety (i.e., the arousal that occurs as a result of negative expectations of cross-group interaction, including fear of sanctions from ingroup members) and the increase of empathy for outgroup members (Pettigrew, 2008a; Vonofacou, Hewstone, Voci et al., 2008).

However, future research needs to focus more on the multilevel factors that curb contact's ability to reduce prejudice (e.g., identity threat), as these are now the most problematic both theoretically and practically, yet the least understood (Pettigrew, 2008b). The fact is that everyday contact between ethnic groups in multicultural settings often bears little resemblance to the ideal contact conditions outlined by the contact hypothesis, with separatist identities, avoidance or intergroup conflict as a result. An important challenge for societies and educational settings alike is thus to reduce the uncertainty and tensions that have evolved in interethnic relationships, to prevent racism and discrimination and to foster healthy intercultural relationships. (Vedder, Horenczyk, Liebkind \&. Nickmans, 2006, cf. chapter by Horenczyk \& Tatar, this volume). 
Scholars seeking to understand and remedy the social problems related to prejudice have common interests with policy makers who in many countries spend considerable amounts of money on interventions aimed at prejudice reduction in schools, neighborhoods and regions beset by intergroup conflict. Given these practical objectives, it is natural to ask what has been learnt about the most effective ways to reduce prejudice. As the school environment constitutes such a salient and important world for children and youth, it is no surprise that Paluck and Green (2009) found in their review that a disproportionate percentage (88\%) of field experiments aimed at evaluating prejudice-reducing techniques are devoted to school-based interventions. While criticizing both the practical and the theoretical value of much prejudice reduction research, Paluck and Green (2009) nonetheless point to the apparent success of various forms of techniques based on narrative and normative communication (e.g., Liebkind \& McAlister, 1999; McAlister, Ama, Barroso, Peters, \& Kelder, 2000) and to their potential for reducing prejudice in the real world through narrative persuasion, the changing of social norms, the increase of cross-group empathy and the use of extended contact.

It is especially the persuasive and positive influence of peers (indirectly via observation or directly via discussion) that is a promising area of prejudice reduction, highlighting the communicative and normative nature of prejudice change (Mähönen, Jasinskaja-Lahti, Liebkind, \& Finell, 2010; Paluck \& Green, 2009). Research has shown that perceived social norms about crossethnic friendship relations partially mediate the association between direct cross-ethnic contact and positive outgroup evaluation (Feddes et al., 2009). However, as cross-ethnic friendships are relatively uncommon compared to same-ethnic friendships (cf. chapter by Spiel and Strohmeier, this volume), a more widespread reduction in prejudice can potentially occur from vicarious experiences of friendship, that is, knowledge of in-group members being friends with outgroup members (Cameron et al., 2006; Vedder at al., 2006), provided that both of these are perceived as typical members of their groups (Cameron \& Rutland, 2008). This Extended Contact Hypothesis 
(Wright, Aron, McLaughlin-Volpe, \& Ropp, 1997; Wright, Aron \& Brody, 2008) maintains, and empirical evidence supports (e.g. Cameron et al., 2006; Liebkind \& McAlister, 1997), that observing an ingroup member having a close relationship with an outgroup member is sufficient for more positive intergroup attitudes to emerge.

However, the immediate and longitudinal effects of direct intergroup friendship are stronger than those of indirect friendship, and both effects are usually found to be stronger for majority than for minority children (Binder et al., 2009; Feddes et al., 2009; Tropp \& Prenovost, 2008). In the long run, therefore, the aim of interventions to improve social psychological acculturation outcomes of immigrant children and youth should aim at lowering the threshold for forming direct crossgroup friendships where the subgroup identities of both are maintained and mutually valued within a sufficiently inclusive superordinate national identity.

The truth about entire genres of prejudice-reduction interventions, including diversity training, educational programs and sensitivity training in health and law enforcement professions, is that they have never been evaluated with experimental methods. Non-experimental research in the field has yielded information about prejudice-reduction program implementation, but has failed to answer the question of what works to reduce prejudice in these real-world settings. (Paluck \& Green, 2009.) However, research evidence on patterns and processes of ethnic and national identification can help to design interventions to reduce intergroup bias; on the one hand, a too strong emphasis on common superordinate identities may actually increase bias in high ingroup identifiers (Crisp \& Beck, 2005), while negative acculturation experiences or an exclusive emphasis on subgroup identities may result in dis-identification from the superordinate group, segregationist identities and hostile intergroup relations (Jasinskaja-Lahti et al., 2009). Thus, while providing immigrants with optimally distinct social identities (Brewer, 1991) and curbing the occurrence of negative acculturation experiences are far from easy tasks, these processes are never the less most likely to lead to the most successful adaptation outcomes. 


\section{References}

Aboud, F. E. (1988). Children and Prejudice. Oxford, UK: Blackwell.

Abrams, D. \& Rutland, A. (2008). The development of subjective group dynamics. In S. R. Levy \& M. Killen (Eds.). Intergroup attitudes and relations in childhood through adulthood (pp. 47-65). Oxford, UK: Oxford University Press.

Ait Ouarasse, O. A., \& Van de Vijver, F. J. R. (2004). Structure and function of the perceived acculturation context of young Moroccans in the Netherlands. International Journal of Psychology, 39, 190-204.

Alba, R. D. (1996). Italian Americans: A Century of Ethnic Change. In S. Pedraza \& R. Rumbaut, (Eds.), Origins and Destinies. Immigration, Race and Ethnicity in America (pp. 172-181). Belmont, CA: Wadsworth Publishing Company.

Allport, G. W. (1954). The nature of prejudice. Reading: Addison-Wesley.

Amiot, C. E., de la Sablonnière, R., Terry, D. J., \& Smith, J. R. (2007). Integration of social identities in the self: Toward a cognitive-developmental model. Personality and Social Psychology Review, 11, 364-388.

Arends-Tóth, J., \& Van de Vijver, F. J. R. (2006). Issues in the conceptualization and assessment of acculturation. In M. H. Bornstein \& L. R. Cote (Eds.), Acculturation and parent child relationships: Measurement and development (pp. 33-62). Mahwah, NJ: Erlbaum.

Banaji, M. R., Baron, A. S., Dunham, Y., \& Olson, K. (2008). The development of intergroup social cognition: Early emergence, implicit nature, and sensitivity to group status. In S. R. Levy \& M. Killen (Eds.), Intergroup attitudes and relations in childhood through adulthood (pp. 87-102). Oxford: Oxford University Press.

Barlow, F. K., Louis, W. L., \& Terry, D. J. (2009). Minority report: Social identity, cognitions of rejection and intergroup anxiety predicting prejudice from one racially marginalized group towards another. European Journal of Social Psychology.

Barrett, M. (2007). Theoretical accounts of how children's knowledge, beliefs and feelings about nations and states develop. In M. Barrett (Ed.): Children's knowledge, beliefs and feelings about nations and national groups (pp. 253-296). Hove: Psychology Press.

Benet-Martinez, V., \& Haritatos, J. (2005). Bicultural Identity Integration (BII): Components and psychosocial antecedents. Journal of Personality, 73, 1015-1050.

Benet-Martinez, V., Leu, J., Lee, F., \& Morris, M. W. (2002). Negotiating Biculturalism: Cultural Frame Switching in Biculturals with Oppositional Versus Compatible Cultural Identities. Journal of CrossCultural Psychology, 33, 492-515. 
Berry, J. W. (1997). Immigration, acculturation, and adaptation. Applied Psychology, 46, 5-34.

Berry, J. W., Phinney, J. S., Sam, D. L., \& Vedder, P. (2006). Immigrant youth: Acculturation, identity, and adaptation. Applied Psychology, 55, 303-332.

Binder, J., Zagefka, H., Brown, R., Funke, F., Kessler, T., \& Mummendey, A. (2009). Does contact reduce prejudice or does prejudice reduce contact? A longitudinal test of the contact hypothesis among majority and minority groups in three European countries. Journal of Personality and Social Psychology, 96, 843-856.

Bohner, G. (2001). Attitudes. In M. Hewstone \& W. Stroebe (Eds.), Introduction to Social Psychology: a European perspective (pp. 239-282). Oxford: Blackwell.

Bourhis, R. Y., Moise, L. C., Perreault, S., \& Senecal, S. (1997). Towards an Interactive Acculturation Model: A social psychological approach. International Journal of Psychology, 32, 369-386.

Branscombe, N. R., Ellemers, N., Spears, R., \& Doosje, B. (1999). The context and content of social identity threat. In N. Ellemers, R. Spears, \& B. Doosje (Eds.), Social identity. Context, commitment, content (pp. 35-58). Oxford: Blackwell Publishers.

Branscombe, N. R., Schmitt, M. T., \& Harvey, R. D. (1999). Perceiving pervasive discrimination among African Americans: Implications for group identification and well-being. Journal of Personality and Social Psychology, 77, 135-149.

Breakwell, G. M. (1986). Coping with threatened identities. London: Methuen \& Co. Ltd.

Brewer, M. B. (1991). The social self: On being the same and different at the same time. Personality and Social Psychology Bulletin, 17, 475-482.

Brewer, M. B. (1999). The psychology of prejudice: Ingroup love or outgroup hate? Journal of Social Issues, 55, 429-444.

Brewer, M. B. (2000). Superodinate goals versus superordinate identity as bases of intergroup cooperation. In D. Capozza \& R. Brown (Eds). Social identity processes: Trends in theory and research (pp. 117132). Thousand Oaks, CA: Sage.

Brewer, M. B., \& Pierce, K. P. (2002). Social identity complexity and outgroup tolerance. Personality and Social Psychology Bulletin, 31, 428-437.

Cameron, L., \& Rutland, A. (2008). An integrative approach to changing children's intergroup attitudes. In S. R. Levy \& M. Killen (Eds.), Intergroup attitudes and relations in childhood through adulthood (pp. 191-203). Oxford: Oxford University Press.

Cameron, L., Rutland, A., Brown, R., \& Douch, R. (2006). Changing children's intergroup attitudes toward refugees: Testing different models of extended contact. Child Development, 77, 1208-1219. 
Chryssochoou, C. (2004). Cultural diversity: Its social psychology. Malden: Blackwell.

Crisp, R. J. \& Beck, S. R. (2005). Reducing intergroup bias: The moderating role of ingroup identification. Group Processes \& Intergoup Relations, 8, 173-185.

Crisp, R. J., Stone, H. C., \& Hall, N. R. (2006). Recategorization and subgroup identification: predicting and preventing threats from common ingroups. Personality and Social Psychology Bulletin, 32, 230243.

Diner, H. (1996). Erin's Children in America: Three Centuries of Irish Immigration to the United States. In S. Pedraza \& R. Rumbaut, (Eds.) Origins and Destinies. Immigration, Race and Ethnicity in America (pp. 161-171). Belmont, CA: Wadsworth Publishing Company.

Dovidio, J. F., Gaertner, S. L., \& Kawakami, K. (2003). Intergroup contact: The past, present, and the future. Group Processes \& Intergroup Relations, 6, 5-21.

Dovidio, J. F., Gaertner, S. L., \& Saguy, T. (2007). Another view of "we": Majority and minority group perspective on a common ingroup identity. In W. Stroebe \& M. Hewstone (Eds.). European review of social psychology, Volume 18, (pp. 296-330). Chichester: John Wiley \& Sons.

Dovidio, J. F., Gaertner, S. L., Saguy, T., \& Halabi, S. (2008). From When to Why. Understanding How Contact Reduces Bias. In U. Wagner, L. R. Tropp, G. Finchilescu, \& C. Tredoux (Eds.), Improving intergroup relations. Building of the legacy of Thomas F. Pettigrew (pp. 75-90). Oxford, UK: Blackwell.

Dovidio, J. F., Glick, P. S., \& Rudman, L. A. (Eds.) (2005). On the nature of prejudice: Fifty years after Allport. Oxford, UK: Blackwell.

Drury, J., \& Reicher, S. (2000). Collective action and psychological change: The emergence of new social identities. British Journal of Social Psychology, 39, 579-604.

Enesco, I., Guerrero, S., Callejas, C., \& Solbes, I. (2008). Intergroup attitudes and reasoning about social exclusion in majority and minority children in Spain. In S. R. Levy \& M. Killen (Eds.), Intergroup attitudes and relations in childhood through adulthood (pp. 105-125). Oxford: Oxford University Press.

Erikson, E. H. (1968). Identity, youth and crisis. New York: W. W. Norton.

Feddes, A. R., Noack, P., \& Rutland, A. (2009). Direct and extended friendship effects on minority and majority children's interethnic attitudes. A longitudinal study. Child Development, 80, 377-90.

Gaertner, S. L., Dovidio, J. F, Guerra, R., Rebelo, M., Monteiro, M. B., Riek, B. M., et al. (2008). The Common In-Group Model. Applications to Children and Adults. In S. R. Levy \& M. Killen (Eds.). Intergroup attitudes and relations in childhood through adulthood (pp. 204-219). Oxford, UK: Oxford University Press. 
Gold, S. J., \& Phillips, B. (1996). Mobility and Continuity Among Eastern European Jews. In S. Pedraza \& R. Rumbaut, (Eds.), Origins and Destinies. Immigration, Race and Ethnicity in America (pp. 182194). Belmont, CA: Wadsworth Publishing Company.

Hewstone, M., Rubin, M., \& Willis, H. (2002). Intergroup bias. Annual Review of Psychology, 53, 575604.

Hodson, G., Dovidio, J. F., \& Esses, V. M. (2003). Ingroup identification as a moderator of positivenegative asymmetry in social discrimination. European Journal of Social Psychology, 33, 215-233.

Horenczyk, G. (2000). Conflicted identities: Acculturation attitudes and the immigrants' construction of their social worlds. In E. Olstein \& G. Horenczyk (Eds.), Language, identity, and immigration (pp. 13-30). Jerusalem: Magnes Press.

Horenczyk, G., \& Ben-Shalom, U. (2001). Multicultural identities and adaptation of young immigrants in Israel. In N. K. Shimahara \& I. Holowinsky \& S. Tomlinson-Clarke (Eds.), Ethnicity, race, and nationality in education: A global perspective (pp. 57-80). Mahwah: Lawrence Erlbaum.

Horenczyk, G., \& Munayer, S. J. (2007). Acculturation orientations toward two majority groups: The case of Palestinian Arab Christian adolescents in Israel. Journal of Cross-Cultural Psychology, $38,76-86$.

Hornsey, M. J., \& Hogg, M. A. (2000a). Assimilation and Diversity: An Integrative Model of Subgroup Relations. Personality \& Social Psychology Review, 4(2), 143-156

Hornsey, M. J., \& Hogg, M. A. (2000b). Subgroup relations: A comparison of mutual intergroup differentiation and common ingroup identity models of prejudice reduction. Personality and Social Psychology Bulletin, 26, 242-256

Hornsey, M. J., \& Jetten, J. (2004). The individual within the group: Balancing the need to belong with the need to be different. Personality and Social Psychology Review, 8, 248-264.

Hutnik, N. (1991). Ethnic minority identity: A social psychological perspective. Oxford: Clarendon.

Jasinskaja-Lahti, I., Liebkind, K., Horenczyk, G., \& Schmitz, P. (2003). The interactive nature of acculturation: Perceived discrimination, acculturation attitudes and stress among young ethnic repatriates in Finland, Israel and Germany. International Journal of Intercultural Relations, 27, 7997.

Jasinskaja-Lahti, I., Liebkind, K., \& Perhoniemi, R. (2006). Perceived discrimination and well-being: a victim study of different immigrant groups. Journal of Community \& Applied Social Psychology, 16, $267-284$. 
Jasinskaja-Lahti, I., Liebkind, K., \& Solheim, E. (2009). To identify or not to identify? National disidentification as an alternative reaction to perceived ethnic discrimination. Applied Psychology: An International Review, 58, 105-128.

Killen, M., \& Levy, S. R. (2008). Intergroup attitudes and relations in childhood through adulthood: An introduction. In S. R. Levy \& M. Killen (Eds.), Intergroup attitudes and relations in childhood through adulthood (pp. 3-15). Oxford, UK: Oxford University Press.

Liebkind, K. (1992). Ethnic identity - Challenging the boundaries of social psychology. In G. M. Breakwell (Ed.), The social psychology of identity and the self concept (pp. 147-185). London: Academic Press (Surrey University Press).

Liebkind, K. (2001). Acculturation. In R. Brown \& S. Gaertner (Eds.), Blackwell handbook of social psychology: Intergroup processes (pp. 386-406). Oxford: Blackwell.

Liebkind, K. (2006). Ethnic identity in acculturation. In D. L. Sam \& J. W. Berry (Eds.), The Cambridge handbook of acculturation (pp. 78-96). Cambridge: Cambridge University Press.

Liebkind, K., \& McAlister, A. L. (1999). Extended contact through peer modelling to promote tolerance in Finland. European Journal of Social Psychology, 29, 765-780.

Liebkind, K., Nyström, S., Honkanummi, E., \& Lange, A. (2004). Group size, group status and dimensions of contact as predictors of intergroup attitudes. Group Processes \& Intergroup Relations, 7, 145-159.

Masgoret, A.-M., \& Ward, C. (2006). Culture learning approach to acculturation. In J. W. Berry, J. S. Phinney, D. Sam, \& P. Vedder (Eds.), Immigrant youth in cultural transition: Acculturation, identity, and adaptation across national contexts (pp. 58-77). Mahwah: Lawrence Erlbaum Associates.

McAlister, A. L., Ama, E., Barroso, C., Peters, R. J., \& Kelder, S. (2000). Promoting tolerance and moral engagement through peer modelling. Cultural Diversity and Ethnic Minority Psychology, 6, 363373.

Moscovici, S., \& Paicheler, G. (1978). Social comparison and social recognition: Two complementary processes of identification. In H. Tajfel (Ed.), Differentiations between social groups: The social psychology of intergroup relations (pp. 251-266). European Monographs in Social Psychology no. 14. London: Academic Press.

Mähönen, T. A., Jasinskaja-Lahti, I., \& Liebkind, K. (2011). Cultural discordance and the polarization of identities. Group Processes \& Intergroup Relations, 4, 505-515. 
Mähönen, T. A., Jasinskaja-Lahti, I., Liebkind, K., \& Finell, E. (2010). Perceived normative pressure and majority adolescents' implicit and explicit attitudes towards immigrants. International Journal of Psychology, 45, 182-189.

Nesdale, D. (2008). Peer group rejection and children's intergroup attitudes. In S. R. Levy \& M. Killen (Eds.). Intergroup attitudes and relations in childhood through adulthood (pp. 32-46). Oxford, UK: Oxford University Press.

Outten, H. R., Schmitt, M. T., Garcia, D. M., \& Branscombe, N. R. (2009). Coping options: Missing links between minority group identification and psychological well-being. Applied Psychology, 58, $146-170$.

Paluck, E. L., \& Green, D. P. (2009). Prejudice reduction: what works? A review and assessment of research and practice. Annual Review of Psychology, 60, 339-367.

Perreault, S., \& Bourhis, R. Y. (1999). Ethnocentrism, social identification and discrimination. Personality and Social Psychology Bulletin, 25, 92-103.

Pettigrew, T. F. (2008a). Reflections on Core Themes of Intergroup Research (pp. 283-303). In U. Wagner, L. R. Tropp, G. Finchilescu, \& C. Tredoux (Eds.), Improving intergroup relations. Building of the legacy of Thomas F. Pettigrew (pp. 75-90). Oxford, UK: Blackwell.

Pettigrew, T. F. (2008b). Future directions for intergroup contact theory and research. International Journal of Intercultural Relations, 32, 187-199.

Pettigrew, T. F., \& Tropp, L. R. (2006). A meta-analytic test of intergroup contact theory. Journal of Personality and Social Psychology, 90, 751-783.

Pfafferott, I. \& Brown, R. (2006). Acculturation preferences of majority and minority adolescents in Germany in the context of society and family. International Journal of Intercultural Relations, 30, 703-717.

Pfeifer, J. H., Rubble, D. N., Bachman, M. A., Alvarez, J. M., Cameron, J. A., \& Fuligni, A. J. (2007). Social identities and intergroup bias in immigrant and nonimmigrant children. Developmental Psychology, 43, 496-507.

Phinney, J. S., \& Alipuria, L. L. (1996). At the interface of culture: Multiethnic/multiracial high school and college students. Journal of Social Psychology, 136, 139-158.

Phinney, J. S., Berry, J. W., Vedder, P., \& Liebkind, K. (2006). The acculturation experience: Attitudes, identities and behaviors of immigrant youth. In J.W. Berry, J. S. Phinney, D. Sam, \& P. Vedder (Eds.), Immigrant youth in cultural transition: Acculturation, identity, and adaptation across national contexts (pp. 71-116). Mahwah, NJ: Lawrence Erlbaum Associates. 
Phinney, J., Ferguson, D. L., \& Tate, J. D. (1997). Intergroup attitudes among ethnic minority adolescents: A causal model. Child Development ,68, 955-969.

Phinney, J. S., Horenczyk, G., Liebkind, K., \& Vedder, P. (2001). Ethnic minority identity: A social psychological perspective. Journal of Social Issues, 57, 493-510.

Phinney, J. S., Jacoby, B., \& Silva, C. (2007). Positive intergroup attitudes: The role of ethnic identity. International Journal of Behavioral Development, 31, 5, 478-490.

Piontkowski, U., Rohmann, A., \& Florack, A. (2002). Concordance of acculturation attitudes and perceived threat. Group Processes \& Intergroup Relations, 5, 221-232.

Reicher, S. (2004). The context of social identity: Domination, resistance, and change. Political Psychology, $25,6,921-945$.

Report of the Community Cohesion Panel. (2004). The end of parallel lives? London: Home Office.

Rivas-Drake, D., Hughes, D., \& Way, N. (2008). A closer look at peer discrimination, ethnic identity, and psychological well-being among urban Chinese American sixth graders. Journal of Youth and Adolescence, 37, 12-21.

Rohmann, A., Florack, A., \& Piontkowski, U. (2006). The role of discordant acculturation attitudes in perceived threat: An analysis of host and immigrant attitudes in Germany. International Journal of Intercultural Relations, 30, 683-702.

Rumbaut, R. G. (2008). Reaping what you sow: Immigration, youth, and reactive ethnicity. Applied Developmental Science, 12, 108-111.

Schmitt, M.T., \& Branscombe, N.R. (2002). The meaning and consequences of perceived discrimination in disadvantaged and privileged social groups. In W. Stroebe \& M. Hewstone (Eds.), European review of social psychology, Volume 12 (pp. 167-199). Chichester: John Wiley \& Sons.

Seaton, E. K., Yip, T., \& Sellers, R. M. (2009). A longitudinal examination of racial identity and racial discrimination among African American adolescents. Child Development, 80, 406-417.

Shelton, J. N., Richeson, J. A., \& Vorauer, J. D. (2006). Threatened identities and interethnic interactions. European Review of Social Psychology, 17, 321-358.

Simon, B. (2004). Identity in modern society. A social psychological perspective. Oxford: Blackwell.

Simon, B., Aufderheide, B., \& Kampmeier, C. (2001). The social psychology of minority - majority relations. In R. Brown \& S. L. Gaertner (Eds.), Blackwell handbook of social psychology: Intergroup processes (pp. 303-323). Oxford: Blackwell.

Simon, B., \& Ruhs, D. (2008). Identity and politicization among Turkish migrants in Germany: The role of dual identification. Journal of Personality and Social Psychology, 95, 1354-66. 
Simon, B., \& Stürmer, S. (2003). Respect for group members: Intragroup determinants of collective identification and group-serving behaviour. Personality and Social Psychology Bulletin, 29, 183-193.

Sindic, D., \& Reicher, D. S. (2009). 'Our way of life is worth defending': Testing a model of attitudes towards superordinate group membership through a study of Scots' attitudes towards Britain. European Journal of Social Psychology, 39, 114-129.

Skrobanek, J. (2009). Perceived discrimination, ethnic identity and the (re-)ethnicisation of youth with a Turkish ethnic background in Germany. Journal of Ethnic and Migration Studies, 35, 535-554.

Snauwaert, B., Soenens, B., Vanbeselaere, N., \& Boen, F. (2003). When integration does not necessarily imply integration. Journal of Cross-Cultural Psychology, 34, 231-239.

Stone, C. H., \& Crisp, R. J. (2007). Superordinate and subgroup Identification as predictors of intergroup evaluation in common ingroup contexts. Group Processes \& Intergroup relations, 10, 493-513.

Tajfel, H. (1978). Social categorization, social identity and social comparison. In H. Tajfel (Ed.), Differentiation between social groups; Studies in the social psychology of intergroup relations (pp. 61-76). London: Academic Press.

Tajfel, H., \& Turner, J. C. (1979). An integrative theory of intergroup conflict. In W. G. Austin \& S. Worchel (Eds.), The social psychology of intergroup relations (pp. 33-47). Monterey: Brooks/Cole.

Tajfel, H., \& Turner, J. C. (1986). The social identity theory of intergroup behavior. In S. Worchel and W. G. Austin (Eds.), Psychology of intergroup relations (pp. 7-24). Chicago: Nelson Hall.

Tropp, L. R., \& Prevonost, M. A. (2008). The Role of Intergroup Contact in predicting Children's Interethnic Attitudes. In S. R. Levy \& M. Killen (Eds.), Intergroup attitudes and relations in childhood through adulthood (pp. 236-248). Oxford, UK: Oxford University Press.

Turner, R. N., \& Brown, R. (2008). Improving children's attitudes toward refugees: An evaluation of a school-based multicultural curriculum and an anti-racist intervention. Journal of Applied Social Psychology, 38, 1295-1328.

Tyler, T. R., \& Blader, S. L. (2003). The group engagement model: Procedural justice, social identity, and cooperative behavior. Personality and Social Psychology Review, 7, 349-361.

Umana-Taylor, A. J., \& Updegraff, K. A. (2007). Latino adolescents' mental health: Exploring the interrelations among discrimination, ethnic identity, cultural orientation, self-esteem, and depressive symptoms. Journal of Adolescence, 30, 549-567.

Vedder, P., Horenczyk, G, Liebkind, K., \&. Nickmans, G. (2006). Ethno-culturally diverse education settings: problems, challenges and solutions. Educational Research Review I, 157-168. 
Verkuyten, M. (1992). Ethnic group preferences and the evaluation of ethnic identity among adolescents in the Netherlands. Journal of Social Psychology, 132(6), 741-751.

Verkuyten, M. (2005). The social psychology of ethnic identity. London: Psychology Press.

Verkuyten, M. (2007). Religious group identification and inter-religious relations: A study among TurkishDutch Muslims. Group Processes \& Intergroup Relations, 10, 341-357.

Verkuyten, M. (2008). Multiculturalism and group evaluations among minority and majority groups. In S. R. Levy \& M. Killen (Eds.). Intergroup attitudes and relations in childhood through adulthood (pp. 157-172). Oxford, UK: Oxford University Press.

Verkuyten, M., \& Yildiz, A. (2007). National (dis)identification, and ethnic and religious identity: A study among Turkish-Dutch Muslims. Personality and Social Psychology Bulletin, 33, 1448-1462.

Verkuyten, M., \& Zaremba, K. (2005). Inter-ethnic relations in a changing political context. Social Psychology Quarterly, 68, 375-386.

Vonofacou, C., Hewstone, M., Voci, A., Paolini, S., Turner, R. N., Tausch, N., Tam, T., Harwood, J., \& Cairns, E. (2008). The Impact of Direct and Extended Cross-Grouip Friendships on Improving Intergroup Relarions (pp. 107-123). In U. Wagner, L. R. Tropp, G. Finchilescu, \& C. Tredoux (Eds.), Improving intergroup relations. Building of the legacy of Thomas F. Pettigrew (pp. 75-90). Oxford, UK: Blackwell.

Waldzus, S., Mummendey, A., \& Wenzel, M. (2005). When “different” means "worse": In-group prototypicality in changing intergroup contexts. Journal of Experimental Social Psychology, 41, 7683.

Williams, D. R., Neighbors, H. W., \& Jackson, J. S. (2003). Racial/ethnic discrimination and health: Findings from community studies. American Journal of Public Health, 93, 200-208.

Wittig, M. A. (2008). A mutual acculturation model for understanding and undermining prejudice among adolescents. In S. R. Levy \& M. Killen (Eds.). Intergroup attitudes and relations in childhood through adulthood (pp. 220-233). Oxford, UK: Oxford University Press.

Wright, S. C., Aron, A., \& Brody, S. M. (2008). Extended Contact and Including Others in the Self. Building on the Allport/Pettigrew legacy (pp. 143-159). In U. Wagner, L. R. Tropp, G. Finchilescu, $\&$ C. Tredoux (Eds.), Improving intergroup relations. Building of the legacy of Thomas F. Pettigrew (pp. 75-90). Oxford, UK: Blackwell.

Wright, S. C., Aron, A., McLaughlin-Volpe, T., \& Ropp, S. A. (1997). The Extended Contact Effect: Knowledge of Cross-Group Friendships and Prejudice. Journal of Personality and Social Psychology, 73, 73-90. 
Figure 8.1. The interplay between negative acculturation experiences, identity processes and outgroup attitudes among Russian-speaking youth living in Finland $(\mathrm{N}=132) \cdot \chi^{2}=656 ; d f=2 ; p=.720$

Note: The model is controlled for age at arrival. Perceived discrimination, ethnic identification and age arrival were set to correlate in the model. All correlations were non-significant. In a hierarchical regression analysis cultural discordance was negatively and significantly related to national

i This approach is more specific than the social psychological approach to immigration research in general presented by Motti-Stefanidi et al. in chapter 5 of this volume. 